\title{
Teaching Computer Science in Moscow Universities: Evolution for Forty Years
}

\author{
Olga Parakhina ${ }^{1}$ and Yuri Polak ${ }^{2}$ \\ ${ }^{1}$ Stankin Technical University, Moscow, Russia \\ parakhina@yandex.ru \\ ${ }^{2}$ Moscow State University, Moscow, Russia \\ yuripolak@yahoo.com
}

\begin{abstract}
The authors share their experiences of teaching computer science at Moscow universities since early 1970s. During this period the technical basis, as well as content and methods of teaching have dramatically changed. The authors state that studying of modern information technologies promotes the creative development of students; and the best way to prepare students for further work is involving them to real research. Some examples of such collaboration of students with academic institutions and high-tech companies are given in the article.
\end{abstract}

Keywords: Computer education, history, hardware, information search.

\section{Early Period of Computer Education}

Education is critical to each citizen's ability to thrive in the knowledge economy. Today's students must develop key 21 st century skills such as familiarity with problem solving, critical thinking and collaboration, and especially information and communication technology. But still half a century ago there were no preconditions for mass training to these disciplines. The quantity of computers was insignificant, they were bulky and expensive, and only skilled experts could communicate with them, using language of machine codes.

Authors (at least one of them) were taught programming since early 60s. Computer training of schoolchildren was spent then only in few special schools and special workshops in some colleges. As early as in 1960 the first graduation of schoolboys with qualification 'programmer' in the Moscow school \#444 took place. First generation computers on electronic lamps ('Ural-1', M-20, 'Elliott') formed a technical base of training. The general-purpose electronic digital computer 'Ural-1' was manufactured in Penza in 1955-1961. It was designed for solving factory planning; accounting, statistical and other problems. Some of its characteristics appear in Table 1 .

During training, schoolchildren carried out various educational tasks, e.g. solving systems of linear equations, matrix operations, functions tabulation etc. Later, during education in the Moscow State University (late 1960th-1970th) authors were engaged in developing algorithms and programming on Algol language. After graduation from the University authors have been conducting pedagogical work in several Moscow 
colleges and universities (MGAPI/VZMI, MGIU/VTUZ-ZIL, MIREA, MESI, MATI etc) using various Soviet-made computers ('Dnepr', 'Minsk', 'Nairi', ES-1020 etc) and different programming languages (Algol, Cobol, Fortran, PL/1, YaAP). That time computer science education everywhere occurred without direct contact between trainees and computers as training system based on batch mode principles. Students gave blanks with texts of programs to their teacher and (after card punching) received results of its performance in a few days in the form of paper listings. Debugging procedure required repeating these operations again and again.

Table 1. Ural-1 Characteristics

\begin{tabular}{|r|l|}
\hline computation speed & 100 operations/sec \\
\hline number base & binary \\
\hline instruction type & single-address \\
\hline number of instructions & 29 \\
\hline $\begin{array}{r}\text { magnetic drum } \\
\text { marage capacity, }\end{array}$ & 1024 \\
\hline punched tape & 10000 \\
\hline magnetic tape & 40000 \\
\hline to printing devices & 100 lines $/ \mathrm{min}$ \\
\hline onto punched tape & $150 \mathrm{codes} / \mathrm{min}$ \\
\hline power consumption & $10 \mathrm{kVA}$ \\
\hline floor space & $75 \mathrm{sq} . \mathrm{m}$ \\
\hline
\end{tabular}

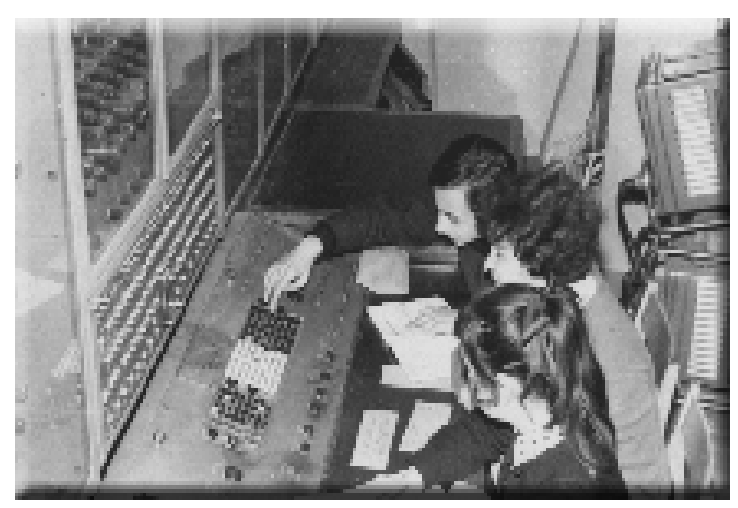

Fig. 1. 'Ural-1' in Moscow school \#444; $1965^{1}$

Prior to the beginning of 1980th training to computer science was conducted only in natural-science, technical and economic colleges and universities. The basic disciplines were programming and algorithmic languages (usually Algol, Fortran or PL/1). That time computer literacy was understood exclusively as skill to

${ }^{1}$ Source: http://schools.keldysh.ru/sch444/01-04.htm 
programming. Educational process had met a number of difficulties because of some problems (and not all of them are solved till this time). First one was the poor technical equipment. In the majority of educational institutions teaching of computer science was carried out then without any computers (there was a popular joke: teacher distributed clay to schoolboys and asked them to mould a computer). Secondly, that is not less important, lack of the qualified teachers, especially in secondary schools. At best, teachers of physics or mathematics taught computer science at schools. Therefore the learning efficiency was enough low.

\section{Back to Dialogue}

Computers have been separated from trainees for years. This situation was changed radically after arising of terminal classes for mainframes and especially desktop microcomputers. The opportunity of dialogue between student and machine has introduced absolutely new qualities into educational process. Acceleration of program debugging and controlling any stages of computational process became possible. Students' understanding of computer functioning had improved, and their interest to lessons had grown [1].

However, the technical equipment for these lessons remained outdated and inefficient. Soviet Union has catastrophically lagged behind the West in computer science and high technology, especially in telecommunication and microprocessor equipment. Some reasons promoted it, but the main were ideological and economic reasons. For many years in the USSR, there was a strict control over information dissemination and any printing or copying equipment. Authorities felt the latent threat in the idea of a personal computer, which assumed information freedom and human development. From the other hand, Soviet economy was extremely nonflexible because of state regulation, and USSR could not quickly organize manufacturing of personal computers. During 'cold war' import of many necessary components was impossible because of COCOM restrictions, so 'Motorola 68000' processor was under strict embargo.

That's why teachers of CS were compelled to use unproductive and inconvenient domestic computers. But even their amount was too far from real needs. For instance,

Table 2. D3-28 Characteristics

\begin{tabular}{|r|l|}
\hline element base & K155, K565 microchips \\
\hline computation speed & 300 operations/sec \\
\hline notation & binary, decimal, hexadecimal \\
\hline RAM & $16 \mathrm{~Kb}$ \\
\hline ROM & $4 \mathrm{~K}$ words \\
\hline & built-in cassette tape recorder \\
\hline power consumption & $150 \mathrm{VA}$ \\
\hline optional periphery & $\begin{array}{l}\text { typewriter, photo input reader, } \\
\text { graph plotter, puncher etc }\end{array}$ \\
\hline weight & $24 \mathrm{~kg}$ \\
\hline &
\end{tabular}


'Electronics D3-28' which was the main training means in MIPT, MADI, VZMI and other institutes in the beginning of 1980th, was made at three plants in total not more than 5000 / year. We remember our expectations within many months in queues of potential users directly at plants, so it was difficult for us to equip classes; it took 5 years to buy 60 computers (and monitors for them from other plant). But even such imperfect equipment has allowed to introduce dialogue methods and BASIC language into educational process. The 'D3-28' characteristics appear in Table 2.

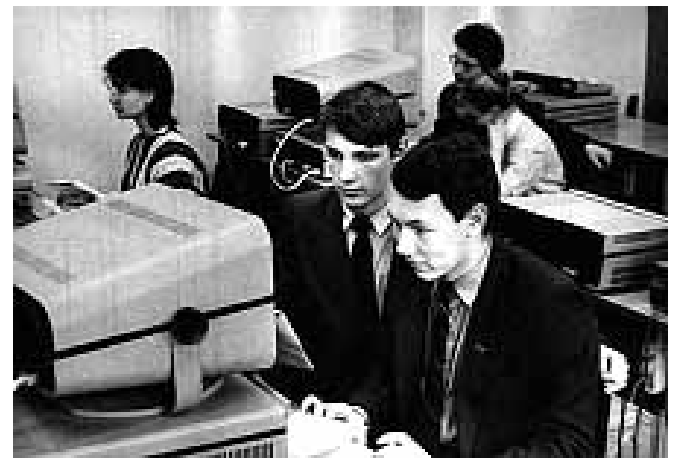

Fig. 2. The class of 'D3-28' computers; $1980^{2}$

\section{Post-'Perestroika' Development}

In 1985, Mr. Gorbachov came to power, and democratization of Russia has begun. The same year obligatory studying of computer science at secondary schools was started. "The basics of informatics and computer science" course for 9-10-graders and teacher's manuals were published under academician A.Ershov's supervision; a methodical magazine 'Computer science and education' had appeared. Domestic educational computers (Agate, BK-0010, Corvette, DVK) formed a hardware basis of CS education. Private initiatives (cooperative societies, joint ventures) had provided import of the personal computer and development software for them (Cyrillic fonts, educational programs etc). The main goal was training pupils to programming and development of algorithmic thinking.

In higher education that period teaching of computer science had extended to humanitarian disciplines, but programming still remained as a main content of education. In 1990th intensive distribution IBM PC in Russia had attracted noticeable changing the content of CS courses at all steps of education. As mass preparation of new equipment users was required, many colleges have made computer science an obligatory subject at all faculties. They finished to teach programming, having passed to IT-training. The motto 'programming is the second literacy' was replaced with the new purpose, 'mass computer literacy'.

Besides hardware, huge changes in the agenda of training courses, in principles of laboratory practical work organization took place. Chalk and cleaning cloth were

${ }^{2}$ Source: http://asoiu.istu.ru/1_3.htm 
replaced by felt-tip pens and markers, then notebooks and projectors. Now lectures are accompanied by multimedia demonstrations, and 1st rate students have skills of professional information search and use specialized software packages.

The higher education information infrastructure was improved as well. Federal university network RUNNet was created in 1994-96; followed by infrastructure for basic network for a science and education RBNet (1996-99). The same time Soros Foundation opened Internet-centers in 33 leading universities. Since 2000 the Federation of Internet Education created about 50 centers for training teachers to possess Internet-technologies. One more private initiative, Intel Teach to the Future Program, is a worldwide professional development effort to help teachers. Launched in 2000, the program has reached more than 3 million teachers in 30 countries $(300$ thousand in Russia). Through this free program, teachers learn from other teachers how, when and where to incorporate technology tools and resources into their lesson plans. Participants create assessment tools and align lessons with educational learning goals and standards.

\section{Contemporary Problems of IT-Education}

One of the main problems in IT-specialists training is a gap between plans of academic education and requirements to graduates, employed in companies. Colleges and universities curricula don't follow modern tendencies of branch, so companies should retrain their staff. It requires not less than half a year, or even 2-3 years for highly skilled employees' formation. In a number of universities there is nobody to teach the specialists of modern level, since many leading teachers and professors have retired, or left abroad, or work in other spheres, not according to their qualification. The average age of the faculty is close to 60 years, and their salary is less than underground cleaners' one.

The quantity of students becomes less as well. Alan Martinson has mentioned demography problems in his presentation during the Russian Outsourcing and Software Summit (ROSS-2006; http://www.soft-outsourcing.com). Here are some figures from his presentation. There are nearby 1.3 million people in the age of 17 in Russia now, but in ten years this quantity is to be decreased approximately up to 650 thousand person, and only then the curve should go upwards. According to Martinson, now Russian colleges graduate 40-50 thousand 'pure' IT-specialists annually, plus 200-250 thousand graduates have base knowledge in IT-technologies. But there are a number of new and actively demanded specializations where education in universities is not conducted at all, or the quantity of graduated experts is not enough. Among such specializations of scarce professionals are project managers; experts on testing; technical writers; manual developers; experts on interface ergonomics; analysts; experts on consulting and project implementation; and lawyers with IT-specialization.

One more essential feature of IT is the high speed of changes of applied technologies. The specialists should update their knowledge essentially at least every 5-6 years. Therefore it is necessary for Russian IT-education to establish close communication to labour market and to provide flexible reaction of education system to its inquiries, and also to develop system of lifelong education and personnel retraining. Russian IT-companies should play an important role in this process. They 
can help in definition of requirements to graduates knowledge and curricula; in launching the centers for additional and certificated training etc.

Many IT-firms actively cooperate with educational institutions, introducing joint programs of training the students of senior rates, so they are prepared for work in ITindustry on a student's bench. Computer business helps to introduce both the newest tendencies in the field of technologies and needs of branch into conservative curricula of higher education system. Here are some examples of such cooperation. The LANIT Company conducts joint activity with the Higher School of Economy, giving an opportunity to students to pass training, and teachers can raise their qualification on company's courses. One more project of LANIT is the computer school 'Expert' organized together with Computational Mathematics Faculty of Moscow State University. Undergraduates and post-graduate students of Moscow Institute for Physics and Technology can maintain their theses for master's degrees and Ph.D using their labour experience in the base company 'Phisicon'. In 2003 in the Nizhniy Novgorod University (under support of Intel Corporation) the Laboratory for Information technologies was created. Its mission is to form a stable system of education of highly skilled experts in modern computer technologies in view of IEEECS and ACM Computing Curricula recommendations for the enterprises of the information industry (naturally, for Intel as well).

In the St.-Petersburg State University chair of system programming is leaded by Prof. Andrew Terekhov who is a head of computer company 'Terkom' simultaneously. He considers that the best way to receive well-educated experts for the company is to train them necessary skills by himself. The teacher should be active researcher; he must tell students about his own research, instead of retelling another achievements. As Terekhov states, the cooperation between university and profile companies interested in carrying out of researches and students training is necessary. Such overlapping of practice and theory is successfully realized in St.-Petersburg State University. Education plans should correspond to international standards. Now only few Russian universities carry out requirements ACM/IEEE Computing Curricula (he estimates a level of his own university's conformity as $80 \%$ ).

The authors have similar experience as well. 10 years ago we have started to use students as researchers in real projects of Russian Academy of sciences. Simultaneously the CS curriculum in the Moscow State University has been modified in view of these practical problems.

\section{On Teaching Computer Science at Moscow State University}

As known, Internet has become not only communicative environment for scientific dialogue but also an invaluable source of information. Network technologies make researchers able to participate in international information exchange, while lack of Internet access rejects them to periphery of science. But sometimes unlucky searchers qualify Internet as 'information dump' (usually they ignore special tools and methods of effective search; don't use inquiries languages and search manuals; don't better their requests with additional keywords and so on). In Moscow State University we have developed a curriculum of computer science for sociologists with special attention to problems of network technologies and information search. Authors' 
course was changed dramatically four times for last 10 years. Each new version tries to meet the needs of the future research work and to approach the students to a level of competent users of the most widespread software. Now our course contains such sections as HTML documents, web design, etiquette of e-mail and - last but not least - methods of information search in Internet.

Studying of modern information technologies promotes the creative development of students. Some of them confidently work with networks, cooperating with the elder researches in search and analysis of information sources for humanitarian disciplines. The best students not only well use the existent search mechanisms, but also actively participate in development of new ones. Since 1996, tens of students of Moscow State University were working in the Central Economics \& Mathematics Institute (CEMI) of the Russian Academy of Science as junior researchers. They participated in support of one of the best directories of Russian Internet resources which was introduced in 1995 in the Laboratory for Network information resources of CEMI (founded by Dr Yuri Polak). Its development required researching the mechanisms of search and making many original decisions; in particular, a special taxonomy (hierarchical set of rubrics) was created. Since 1996 our directory is available online; its origin was our database with more than 50,000 annotated records of information resources grouped on 300+ themes, which described both Russian sites and also relevant foreign materials [2]. Besides the standard search programs were used for the database updating. The students of MSU had brought a significant contribution to development of this unique catalogue of Runet (Russian Internet) by supporting a database and monitoring the information resources. They took active part in checking URLs, writing annotations and reviews. Many thematic reviews prepared by the students were published in well-known professional editions such as bimonthly magazine 'Russia's Information Resources', non-periodical 'Russian Internet Navigator' and PC Week (Russian Edition).

Our collective had won a prize in competition of young researchers of Academy of Science on fundamental and applied researches. Our students have also developed a number of well-designed web-sites with rich content, including unofficial pages of psychological department flogiston.ru and sociological department www.nir.ru/socio/ of Moscow University. One more our project has been executed for the company Yandex, Russian portal \#1. Its heart is a search engine with more than billion indexed documents of total volume about 30 TB. It has the largest database on Runet, vastly outstripping its nearest competitor. In early 2000s Yandex introduced a new advanced built-in catalogue. A group of MSU students took part in development of its taxonomies, database fulfilment and stuff training. The convergence of search engine and a catalogue allows overcoming their immanent defects: manually updated directories aren't enough full and actual; while the output of automatic search engine contains a lot of irrelevant links. This catalogue is structured specifically for the Russian market, showing web-sites based upon Yandex's 'Citation Index', a method of ranking web-resources by external references. This has proven very popular and the catalogue has quickly gained market share from the competition.

The amount and variety of Internet resources lead to complex taxonomies of universal Internet directories. As a possible solution to the problem, in Yandex catalogue a faceted classification was used. Facet analysis was developed as a tool for the organization of document collections in technical, scientific and social scientific 
fields, where it was highly effective in the storage and retrieval. Currently, facet analysis is used primarily to create classifications for the physical arrangement of documents (or document surrogates). In Yandex built-in directory such facets as 'genre', 'geographical region', 'source of information' and so on are used, so the search process become quicker and its results are more relevant.

The work in network environment expands mental outlook of the students, reduces time needed for fulfilment educational tasks, supplies them with unique information, improves their knowledge of foreign languages. Choosing the optimum decision of a search task, the students are being trained in network technologies and logical thought; develop their skills of information processing. These skills are necessary for their further research work and other activities [3-5].

We do not know how the world of information technologies will change in seven to ten years. However, we are sure that this progress will noticeably change our life and, as consequence, educational curricula. We will wait these new challenges with great interest and try to meet it adequately.

\section{References}

[1] Polak, Y.: Computerization of Education: Problems of Mass Learning. Problems of Economics 29(12) (1987)

[2] Polak, Y.: Internet in Russia, Russia in Internet. In: Proceedings of 22nd International Online Information Meeting 1998, London (1998)

[3] Polak, Y.: Information search in Russian Internet on the eve of 2000. In: 1st International Conference and Exhibition, Internet: Technologies and Services - IEEE (October 1999)

[4] Polak, Y.: Network technologies and creative development of students. In: International Conference TET 2001, Telecommunications for Education and Training, Praha (2001)

[5] Parakhina, O., Polak, Y.: Competitive and Game Components in Teaching Search Strategies. In: Proceedings of the 4th International Workshop on Computer Science and Information Technologies, CSIT 2002, Patras, Greece (2002) 